\title{
Impact of ocean acidification and elevated temperatures on early juveniles of the polar shelled pteropod Limacina helicina: mortality, shell degradation, and shell growth
}

\author{
S. Lischka, J. Büdenbender, T. Boxhammer, and U. Riebesell \\ Leibniz-Institute for Marine Sciences (IFM-GEOMAR), Kiel, Germany \\ Received: 27 October 2010 - Published in Biogeosciences Discuss.: 5 November 2010 \\ Revised: 11 April 2011 - Accepted: 12 April 2011 - Published: 15 April 2011
}

\begin{abstract}
Due to their aragonitic shell, thecosome pteropods may be particularly vulnerable to ocean acidification driven by anthropogenic $\mathrm{CO}_{2}$ emissions. This applies specifically to species inhabiting Arctic surface waters that are projected to become temporarily and locally undersaturated with respect to aragonite as early as 2016 . This study investigated the effects of rising partial pressure of $\mathrm{CO}_{2}\left(p \mathrm{CO}_{2}\right)$ and elevated temperature on pre-winter juveniles of the polar pteropod Limacina helicina. After a 29 day experiment in September/October 2009 at three different temperatures and under $p \mathrm{CO}_{2}$ scenarios projected for this century, mortality, shell degradation, shell diameter and shell increment were investigated. Temperature and $p \mathrm{CO}_{2}$ had a significant effect on mortality, but temperature was the overriding factor. Shell diameter, shell increment and shell degradation were significantly impacted by $p \mathrm{CO}_{2}$ but not by temperature. Mortality was $46 \%$ higher at $8{ }^{\circ} \mathrm{C}$ than at in situ temperature $\left(3^{\circ} \mathrm{C}\right)$, and $14 \%$ higher at $1100 \mu$ atm than at $230 \mu a t m$. Shell diameter and increment were reduced by 10 and $12 \%$ at $1100 \mu$ atm and $230 \mu \mathrm{atm}$, respectively, and shell degradation was $41 \%$ higher at elevated compared to ambient $p \mathrm{CO}_{2}$. We conclude that pre-winter juveniles will be negatively affected by both rising temperature and $p \mathrm{CO}_{2}$ which may result in a possible decline in abundance of the overwintering population, the basis for next year's reproduction.
\end{abstract}

\section{Introduction}

Anthropogenic $\mathrm{CO}_{2}$ emissions affect the seawater carbonate chemistry and cause a decrease of seawater $\mathrm{pH}$ (termed ocean acidification) and carbonate ions in the worlds' oceans,

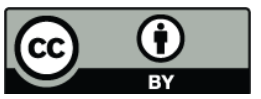

Correspondence to: S. Lischka (slischka@ifm-geomar.de) thereby also diminishing the saturation state of seawater with respect to calcite and aragonite. This effect is strongest in high-latitude surface waters, which are also experiencing the steepest increase in surface ocean temperature (Orr et al., 2005; Steinacher et al., 2009). Due to increasing $\mathrm{CO}_{2}$ emissions since the industrial revolution, global mean surface temperatures have risen by $0.76^{\circ} \mathrm{C}$ and global mean seawater $\mathrm{pH}$ has decreased by 0.1 unit (IPCC, 2007).

Calcite and aragonite are two common types of calcium carbonate secreted by marine organisms. Surface waters of the Arctic are specifically affected by carbonate undersaturation due to the high solubility of $\mathrm{CO}_{2}$ in cold waters, for example in the Canada Basin, undersaturation with respect to aragonite was already detected in 2008 (Steinacher et al., 2009; Yamamoto-Kawai et al., 2009).

Changes in the carbonate chemistry can have severe consequences for marine organisms, particularly to those that build skeletons, shells, and tests of biogenic calcium carbonate. For instance, reduced calcification rates in corals, coralline macroalgae, coccolithophorids, bivalves, and echinoderms have been reported during the last years as a consequence of rising $\mathrm{CO}_{2}$ partial pressures (e.g. Gattuso et al., 1999; Riebesell et al., 2000; Gazeau et al., 2007; Fabry et al., 2008). On contrast, a recent study by Gutowska et al. (2010) revealed increased calcification in the cuttlebone of the cephalopod Sepia officinalis during exposure to elevated $\mathrm{CO}_{2}$ partial pressures. Hence, organisms' response of calcification to carbonate system variations is diverse.

A widely held view, as articulated by Wilson (1973), has been that "living things during early developmental stages are more sensitive than at any other time in their life cycle to adverse influences in the environment". Also with respect to ocean acidification, several studies corroborate this view in that early developmental and reproductive stages of calcifiers are the most vulnerable stages within a life cycle (e.g. Kurihara et al., 2007; Kurihara, 2008; Clark et al., 2009;

Published by Copernicus Publications on behalf of the European Geosciences Union. 
Comeau at al., 2010a). These authors reported, for example, on retarded larval development, reduced shell mineralization/calcification, increased mortality and degradation of larval skeleton in sea urchin and pteropod larvae, respectively. Acting on early developmental and reproductive stages, ocean acidification can have a direct impact on the size of the population, reduce fitness and increase mortality of the offspring (Kurihara, 2008). Thus it can lead to changes in species distribution and abundances that could propagate through multiple trophic levels of the marine food web (Guinotte and Fabry, 2008).

Thecosome pteropods are widely distributed small-sized holoplanktonic marine mollusks. While their species diversity is high in tropical regions, only two epipelagic species, both of the genus Limacina, occur in temperate areas of the North Atlantic and in Arctic regions (van der Spoel, 1967). In northern and polar regions, pteropods can dominate zooplankton communities at times and are key species in epipelagic food webs both as consumers of and prey for various marine organisms, including commercially important fish, seabirds and baleen whales (Gilmer and Harbison, 1991; Falk-Petersen et al., 2001; Karnovsky et al., 2008).

Shelled pteropods of the genus Limacina (L. helicina, $L$. retroversa) also contribute significantly to vertical fluxes of both organic matter and biogenic calcium carbonate (Berner and Honjo, 1981; Bathmann et al., 1991; Hunt et al., 2008). Furthermore, thecosomes have a very thin and fragile shell made of aragonite, a particularly soluble form of calcium carbonate, and are the main planktonic producers of aragonite in the worlds' oceans (Lalli and Gilmer, 1989; Seibel et al., 2007). Due to the chemical structure of their shell, pteropods are expected to be among the first major group of calcifying organisms to be adversely effected by undersaturation in $\mathrm{CaCO}_{3}$ (Orr et al., 2005; Seibel et al., 2007). Hence, due to its polar distribution, this will specifically apply to Limacina helicina.

In Svalbard waters Limacina helicina has a one-year life cycle. It develops to adults in early summer, and after reproduction in July/August their veligers grow to juveniles that overwinter until the next spring before development is completed (Gannefors et al., 2005; Lischka unpublished data). To cope with the high seasonality of food supply, many polar organisms reduce their metabolism to save energy and/or live on their energy reserves during winter (e.g. Hirche, 1996; Hagen and Auel, 2001; Lee et al., 2006). As for L. helicina it is not clear whether or not it lowers its metabolism during overwintering and, if it does, to what extent. Juveniles accumulate lipids and probably utilize them during the dark period (Gannefors et al., 2005). Hence with respect to ocean acidification, L. helicina will have to withstand the most threatened period in a presumably vulnerable life stage and time.

Recently, the response to elevated partial pressure of $\mathrm{CO}_{2}$ $\left(p \mathrm{CO}_{2}\right)$ of adult L. helicina was investigated by Comeau et al. $(2009,2010 b)$. In the later study, calcification was re- duced as a function of $p \mathrm{CO}_{2}$ at control and elevated temperature, whereas respiration was unaffected at control temperature but increased significantly as a function of $p \mathrm{CO}_{2}$ at higher temperature. Hence, temperature can be a contributing factor to a species' response to changing $p \mathrm{CO}_{2}$. In another investigation, Comeau and co-workers studied larvae of the mediterranean species Cavolinia inflexa and reported on malformations, reduced shell growth and even shell-less, though still alive, larvae grown under low $\mathrm{pH}$, respectively (Comeau et al., 2010a).

Furthermore, studies of pteropod shells collected in deepsea sediment and traps provide evidence that shell integrity is lost with increasing degree of dissolution (Almogi-Labin et al., 1986; Acker and Byrne, 1989; Haddad and Droxler, 1996; Gerhardt et al., 2000; Manno et al., 2007). However, it is not possible from these findings to conclude on the effect of undersaturated waters on the shell of living pteropods. In fact, shell dissolution in live pteropods (Clio pyramidata) has so far only been described by Orr et al. (2005) by a coincidental observation and in larvae of Cavolinia inflexa by Comeau et al. (2010a).

The present paper reports on the first experimental study that focuses on the combined effects of ocean acidification and elevated temperature on juveniles of the pteropod L. helicina from the Arctic Kongsfjord (Svalbard) prior to the overwintering period (mid September to end of October 2009). To study the synergistic effects of elevated $p \mathrm{CO}_{2}$ and temperature, incubation experiments were carried out at three different temperatures and four $p \mathrm{CO}_{2}$ partial pressures to qualitatively assess the impact on species mortality, shell degradation, and shell growth. Levels of $p \mathrm{CO}_{2}$ chosen cover a range from pre-industrial values to levels projected to occur within this century (according to the A2 scenario in the report of the Intergovernmental Panel on Climate Change, IPCC, 2007). The combination of three temperatures and four $p \mathrm{CO}_{2}$ levels permitted conclusions regarding the separate, as well as combined, effects of temperature and $\mathrm{CO}_{2}$.

\section{Material and methods}

\subsection{Field sampling of pteropods}

Juvenile Limacina helicina (Pteropoda, Thecosomata) were collected in Kongsfjord (northwest Spitsbergen) between 21 and 23 September 2009 using a plankton net $(70 \mu \mathrm{m}$ mesh size, $0.2 \mathrm{~m}^{2}$ mouth opening, 11 plastic cod end) onboard R/V Teisten. Integrated vertical hauls were taken in the deepest accessible part of the fjord from 300 or $200 \mathrm{~m}$ depth to the surface to allow collection of the deeper living overwintering individuals (Fig. 1). Onboard, freshly collected pteropods were stored in 201 plastic containers in ambient seawater, and immediately transported to the Kings Bay Marine Laboratory where they were transferred into filtered seawater. About 200 individuals were caught per haul, less than $5 \%$ were damaged 
due to collection. In the laboratory, specimens were kept for 1 to 2 days at in situ temperature (approximately $3^{\circ} \mathrm{C}$ ) in $1 \mu \mathrm{m}$ filtered seawater until the start of experiments. Seawater supplied in the Marine Laboratory was pumped at $80 \mathrm{~m}$ depth from Kongsfjord and filtered through $20 \mu \mathrm{m}$ filters. For experimental purpose, seawater was additionally filtered through Whatman GF/B filters (approximately retaining particles larger than $1 \mu \mathrm{m}$ ). Furthermore, to characterize abiotic parameters, depth, temperature, and salinity were measured with a STD/CTD model SD-204 (SAIV A/S, Bergen, Norway) prior to each sampling event.

\subsection{Calcein staining}

For qualitative assessment of shell growth under different temperature and $p \mathrm{CO}_{2}$ conditions, pteropods were stained in a calcein bath $\left(50 \mathrm{mg}^{-1}\right)$ for $1 \mathrm{~h}$ prior to incubation at experimental conditions. After staining, animals were rinsed with filtered seawater four times to remove excessive dye. Only actively moving individuals were taken for the experiments. Under UV-light, calcein has its fluorescence maximum at $515 \mathrm{~nm}$ (green) and marks the aperture margin at the time of staining (Comeau et al., 2009).

\subsection{Experimental setup}

In order to simulate past, present and future carbonate chemistries (atmospheric $p \mathrm{CO}_{2}$ levels), $\mathrm{GF} / \mathrm{B}$ filtered seawater was bubbled with air enriched with $\mathrm{CO}_{2}$ using gas mixing pumps (Wösthoff, Germany) to $\mathrm{CO}_{2}$ levels of 180, 380, 750 and $1150 \mathrm{ppm} p \mathrm{CO}_{2}$ (target values) in storage containers at three temperatures $\left(3,5.5\right.$, and $\left.8^{\circ} \mathrm{C}\right)$. Temperatures were chosen according to a projected $1-2^{\circ} \mathrm{C}$ temperature increase for the upper 100-200 m of the Arctic ocean (Steinacher et al., 2009). The natural temperature range of Limacina helicina goes from $-0.4{ }^{\circ} \mathrm{C}$ to $+4{ }^{\circ} \mathrm{C}$, infrequently up to $7^{\circ} \mathrm{C}$ (van der Spoel, 1967). Hence, experimental temperatures are within its natural range $\left(3\right.$ and $5.5^{\circ} \mathrm{C}$ ) and according to a projected $2^{\circ} \mathrm{C}$ increase slightly above the upper temperature limit $\left(8^{\circ} \mathrm{C}\right)$. Six replicates were set up for each of the twelve treatment combinations. Prior to pipetting 10 optically clean and actively moving juvenile $L$. helicina into each of the $440 \mathrm{ml}$ jars (= one replicate), $5 \mathrm{ml}$ filtered seawater were put in the jars to accommodate pteropods before filling the jars with the manipulated seawater. The whole procedure was done on crushed ice. After completion of all replicates of one temperature treatment $\left(6\right.$ replicates $\times 4 p \mathrm{CO}_{2}$ levels $=24$ jars), jars were filled with the manipulated seawater at treatment temperature, closed with an air-tight lid and stored in a water bath in a climate room at the experimental temperature. Incubations were performed in darkness in order to mimic the conditions at the depth of collection. Directly before filling experimental jars with manipulated seawater, water samples of each of the $\mathrm{CO}_{2}$ manipulated seawater storage containers were taken for total alkalinity $\left(A_{\mathrm{T}}\right)$ and nutrients

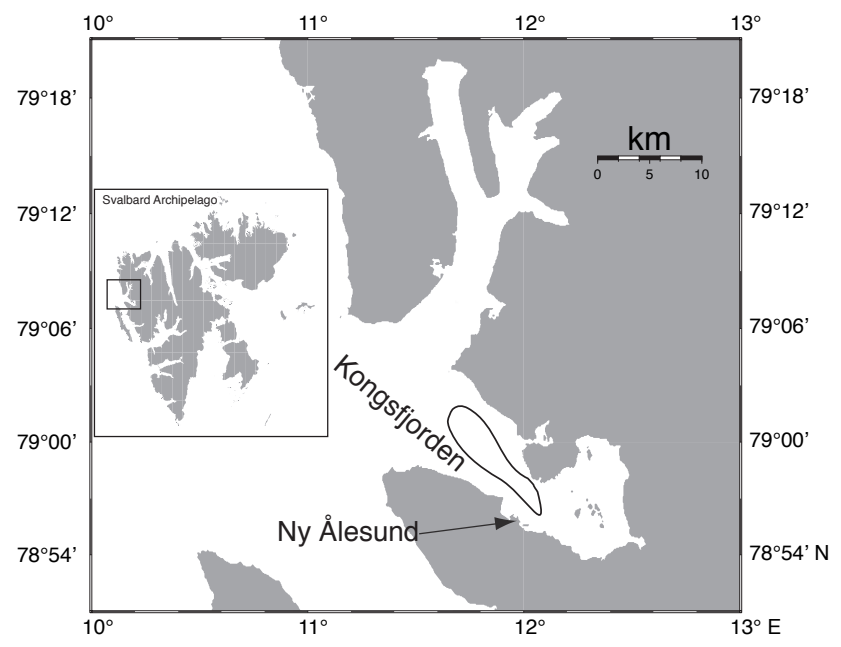

Fig. 1. Map of Kongsford highlighting the sampling area.

and $\mathrm{pH}$ on the total scale $\left(p \mathrm{H}_{\mathrm{T}}\right)$ was measured (see below). Nutrient samples were immediately deep-frozen $\left(-20^{\circ} \mathrm{C}\right)$ whereas $A_{\mathrm{T}}$ samples were poisoned with $\mathrm{HgCl}_{2}$ and stored at $4{ }^{\circ} \mathrm{C}$ (Dickson et al., 2007). After 29 days the experiment was terminated. Before harvesting juvenile Limacina helicina, $p \mathrm{H}_{\mathrm{T}}$ was measured in each jar and water samples for $A_{\mathrm{T}}$ and nutrient analyses were taken. Subsequently, juveniles were collected from the jars and inspected for sur$\mathrm{vival} /$ mortality under a stereomicroscope and after rinsing in Milli-Q water, live (actively moving) individuals were preserved in $70 \% \mathrm{EtOH}$ until inspection for shell degradation state and shell increment. Additionally, fjord water samples were taken for in situ $A_{\mathrm{T}}$, dissolved inorganic carbon $\left(C_{\mathrm{T}}\right)$ and nutrient measurements.

\subsection{Analyses of the carbonate chemistry}

$\mathrm{pH}$ on the total scale was calculated from voltage readings according to SOP6a in Dickson et al. (2007). Instead of using TRIS buffers we used certified reference material (CRM) with a known $\mathrm{pH}$ calculated from known $A_{\mathrm{T}}$ and $C_{\mathrm{T}}$ (Prof. A. Dickson, Scripps Institution of Oceanography, La Jolla, California) as standard. Measurements were performed using a pH Mobile $826 \mathrm{pH}$ meter (Metrohm, Switzerland), precision was within $0.2 \mathrm{mV}$ units.

Total alkalinity $\left(A_{\mathrm{T}}\right)$ was determined using a potentiometric titration device (Titrando 808, Metrohm; Bradshaw et al., 1981). $A_{\mathrm{T}}$ was calculated from the Gran function as described by Dickson et al. (2003). The accuracy was determined by measuring CRM's as described for the $\mathrm{pH}$ measurements and precision was within $2 \mu \mathrm{mol} \mathrm{kg}{ }^{-1}$ (max. difference between two replicate measurements). For fjord water, dissolved inorganic carbon $\left(C_{\mathrm{T}}\right)$ was quantified with continuous-flow analysis (Bran \& Luebbe QUAATRO photometer) according to Stoll et al. (2001). $A_{\mathrm{T}}$ accuracy was between 1 to $15 \mu \mathrm{mol} \mathrm{kg}{ }^{-1}$ (differences between measured 


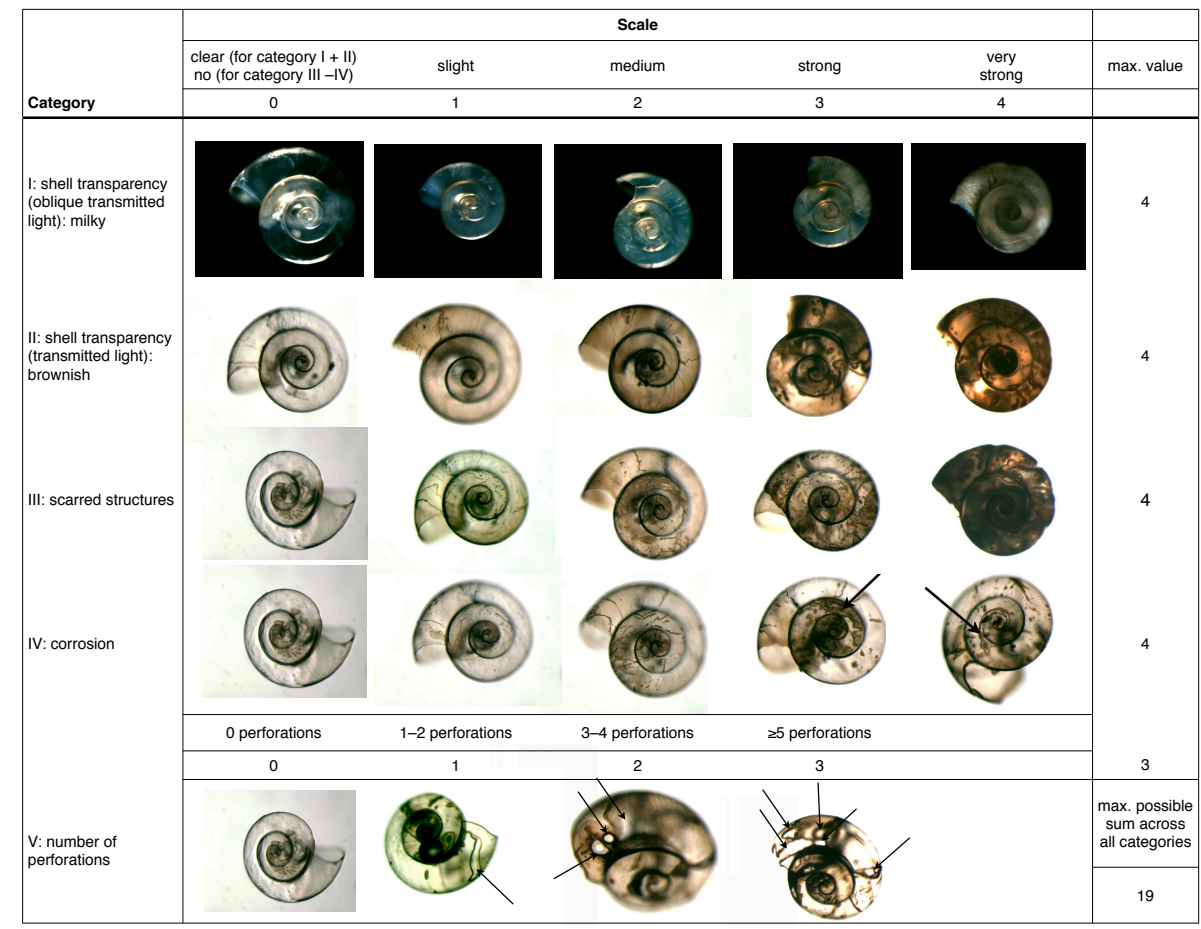

Fig. 2. Categories of shell degradation (I to V) and their levels of conspicuities on a scale from 0 to 4 (for category I to IV) and 0 to 3 (for category V). Examples for each level and its associated score in each category are shown. See also Figure 3 for category IV and V.

and target $A_{\mathrm{T}}$ in the CRM's from A. Dickson et al. (2003) depending on prepared solutions and temperatures etc.) and $C_{\mathrm{T}}$ accuracy was between 40 to $50 \mu \mathrm{mol} \mathrm{kg}{ }^{-1}$. Remaining carbonate system parameters for the experiments and fjord were calculated from $A_{\mathrm{T}}$ and $\mathrm{pH}$, and $A_{\mathrm{T}}$ and $C_{\mathrm{T}}$, respectively with the free software CO2SYS (Pierrot and Wallace, 2006) using the constants from Mehrbach et al. (1973) refitted by Dickson and Millero (1987). Nutrients were analyzed according to Koroleff and Grasshof (1983).

$\mathrm{CO}_{2}$ partial pressures at the start of the experiment differed slightly between replicates of the same $\mathrm{CO}_{2}$ level, with consistently lower values at lower temperatures. This difference is attributed to temperature dependent equilibration rates, which increase with increasing temperature. Apparently three days of bubbling with $\mathrm{CO}_{2}$ /air gas mixtures were insufficient to achieve full equilibration of the medium.

\subsection{Mortality}

After termination of the experiment, all juvenile Limacina helicina were inspected for survival under a stereomicroscope. For this, individuals were categorized optically into five different stages of activity ( $\mathrm{I}=$ highest activity, $\mathrm{V}=$ no activity, identified as dead)

- Stage I: animal expanded, actively moving, soft tissue appears clear and in good condition
- Stage II: animal retracted, actively moving inside shell, soft tissue appears clear and in good condition

- Stage III: animal retracted, no discernable active movements, but soft tissue appears clear and in good condition, individual most likely alive

- Stage IV: animal retracted, no discernable movements, soft tissue appears decomposed, individual most likely dead

- Stage V: animal retracted, soft tissue appears strongly decomposed, individual clearly dead.

For statistical evaluation stages I-III (alive) and IV-V (dead) were pooled.

\subsection{Shell degradation}

The soft tissue was removed with chlorine bleach $(24 \mathrm{~h}$ at room temperature) prior to analyzing shell degradation and growth (see below).

Shell integrity of all surviving individuals of all replicates was examined for surface degradation under a stereomicroscope (Leica MZ 16F). Pteropod shells lose their integrity with increasing dissolution (e.g. Almogi-Labin et al., 1986; Gerhardt et al., 2000). Similar to Gerhardt et al. (2000), shell degradation was qualitatively described according to five categories, which are briefly described in the following (Fig. 2): 


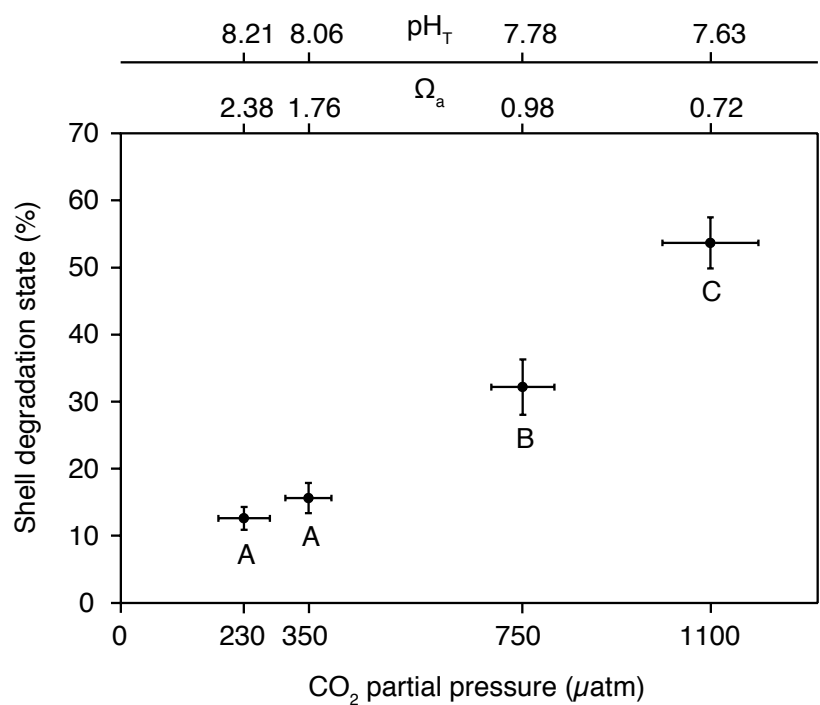

Fig. 3. Percent shell degradation of Limacina helicina after 29 days of incubation. Mean for the effect of $p \mathrm{CO}_{2}$. Vertical bars denote 0.95 confidence intervals for shell degradation while horizontal bars denote 0.95 confidence intervals for $p \mathrm{CO}_{2}$. Results from PERMANOVA pair-wise tests are depicted by letters with levels not connected by same letter being significantly different.

- Category I: Shell transparency (applying oblique transmitted light with mirror in an acute angle to the source of light). Shells were evaluated according to their transparency under oblique transmitted light. The scale extends from total transparency/clearness to different states of milky and cloudy shells, respectively.

- Category II: Shell transparency (applying transmitted light, with mirror in an obtuse angle to the source of light). Using transmitted light, shells appear brownish to various extents.

- Category III: Scarred structures. Category III describes the frequency of scarred structures of any kind.

- Category IV: Corrosion. Category IV describes the deepness of scarred structures in the shell that can be estimated by focusing the stereomicroscope, hence category IV describes the severity of corrosion.

- Category V: Perforation. In this category the number of holes in the shell is considered.

The condition of a single shell according to the different categories was described on a scale from 0 to 4 for categories I to IV and 0 to 3 for category V. The maximum possible sum of the five categories was 19 for a single shell. The maximum value was calculated for all inspected shells and graphically depicted as percentage of maximum possible surface degradation (see Fig. 3). For statistical evaluation, raw scores for each category were used (see below). In

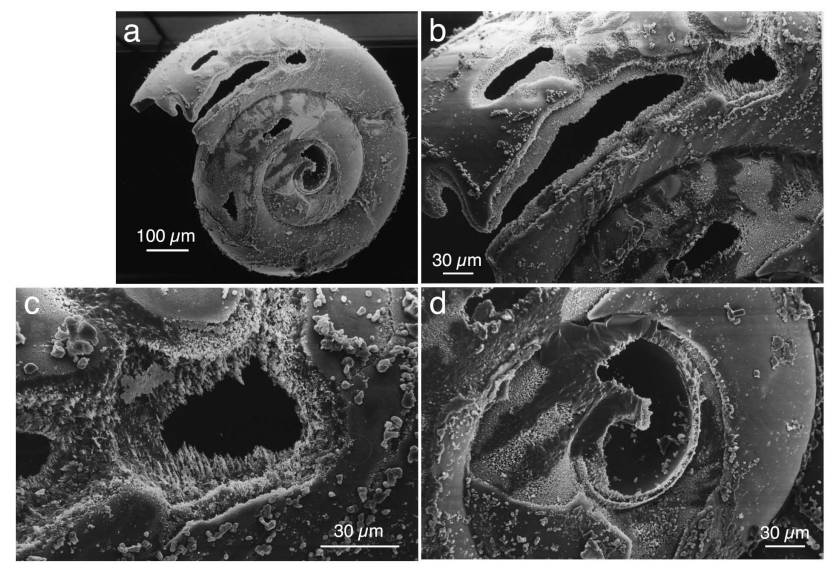

Fig. 4. Scanning electron micrographs (SEM) of representative Limacina helicina reared at $3^{\circ} \mathrm{C}$ and $1100 \mu$ atm to illustrate shell degradation state specifically with respect to category IV and V. Magnification and scale bars are shown. The individual shown is the same as the one shown in Table 1 for category $\mathrm{V}$ with $\geq 5$ perforations.

some cases, shells were mechanically damaged during processing. However, perforations due to corrosion can usually be distinguished from those resulting from mechanical damage. Therefore, only those perforations were counted in category $\mathrm{V}$ that could be identified as non-mechanical. Hence, shell surface degradation with respect to category $\mathrm{V}$ is underestimated.

Additionally, selected shells were examined by Scanning Electron Microscope (CamScan-CS-44, Institute of Geosciences, Kiel University) to illustrate shell degradation state in categories IV and V (Fig. 4).

\subsection{Analysis of shell growth}

Shell growth estimated from calcein staining was measured on a Leica MZ 16 F stereomicroscope equipped with a UVepifluorescence lamp and the Leica Application Suite 3.5.0. To standardize for individual size differences, not only the shell increment was measured but also the shell diameter and the ratio of shell increment to shell diameter was used for comparison between temperature treatments and $\mathrm{CO}_{2} \mathrm{lev}$ els. One individual of each of the 6 replicates was analyzed (Fig. 5).

\subsection{Statistics}

Multifactorial analysis was performed to test for significant effects of the factors temperature and $p \mathrm{CO}_{2}$ on mortality, shell diameter and the ratio of shell increment to shell diameter using a general linear model Type IV (GLM) for equal sample size in case of mortality and a GLM Type III model for unequal sample size in case of shell diameter and shell increment/diameter. Percentage data of mortality 
Table 1. Mean carbonate system parameters calculated from samples taken from the prepared manipulated seawater at start and from all experimental jars at the end of the experimental period. The treatment column refers to target temperature and $p \mathrm{CO}_{2}$, of which the $p \mathrm{CO}_{2}$ levels refer to glacial partial pressure $\mathrm{CO}_{2}(180 \mu \mathrm{atm}, 18 \mathrm{kyr} \mathrm{BC})$, present day $p \mathrm{CO}_{2}(380 \mu \mathrm{atm}$, year 1990$)$, high $p \mathrm{CO} 2 \mathrm{I}(750 \mu \mathrm{atm}$, year 2080), and high $p \mathrm{CO}_{2} \mathrm{II}\left(1150 \mu \mathrm{atm},>\right.$ year 2100). The concentration of total $\mathrm{CO}_{2}\left(C_{\mathrm{T}}\right)$, partial pressure of $\mathrm{CO}_{2}\left(p \mathrm{CO}_{2}\right)$, and the saturation state of aragonite $\left(\Omega_{a}\right)$ were derived from $\mathrm{pH}_{\mathrm{T}}$, total alkalinity $\left(A_{\mathrm{T}}\right)$, salinity $(S)$ and temperature $(T)$. Si is silicate.

\begin{tabular}{|c|c|c|c|c|c|c|c|c|c|c|c|c|c|c|c|c|}
\hline \multicolumn{2}{|c|}{ Treatment } & \multirow[t]{2}{*}{$S$} & \multicolumn{2}{|c|}{$\begin{array}{c}T \\
\left({ }^{\circ} \mathrm{C}\right)\end{array}$} & \multicolumn{2}{|c|}{$\begin{array}{c}A_{\mathrm{T}} \\
\left(\mu \mathrm{mol} \mathrm{kg}{ }^{-1}\right)\end{array}$} & \multicolumn{2}{|c|}{$\mathrm{pH}_{\mathrm{T}}$} & \multicolumn{2}{|c|}{$\begin{array}{c}C_{\mathrm{T}} \\
\left(\mu \mathrm{mol} \mathrm{kg}{ }^{-1}\right)\end{array}$} & \multicolumn{2}{|c|}{$\begin{array}{l}p \mathrm{CO}_{2} \\
\text { ( } \mu \text { atm) }\end{array}$} & \multicolumn{2}{|c|}{$\Omega_{a}$} & \multicolumn{2}{|c|}{$\left.\begin{array}{c}\mathrm{Si} \\
(\mu \mathrm{mol} \mathrm{g} \\
-1\end{array}\right)$} \\
\hline $\begin{array}{c}\mathrm{T} \\
\left({ }^{\circ} \mathrm{C}\right)\end{array}$ & $\begin{array}{r}p \mathrm{CO}_{2} \\
(\mu \mathrm{atm})\end{array}$ & & start & end & start & end & start & end & start & end & start & end & start & end & start & end \\
\hline \multirow[t]{4}{*}{3} & 180 & 34.7 & 3.5 & 3.6 & 2280 & 2288 & 8.27 & 8.28 & 2045 & 2047 & 216 & 211 & 2.45 & 2.51 & 2.63 & 6.49 \\
\hline & 380 & 34.7 & 3.3 & 3.5 & 2280 & 2287 & 8.12 & 8 & 2115 & 2164 & 323 & 435 & 1.81 & 1.45 & 2.63 & 7.27 \\
\hline & 750 & 34.7 & 3.1 & 3.6 & 2280 & 2291 & 7.81 & 7.78 & 2223 & 2241 & 703 & 764 & 0.95 & 0.91 & 2.63 & 11.82 \\
\hline & 1150 & 34.7 & 3 & 3.5 & 2280 & 2296 & 7.69 & 7.62 & 2260 & 2291 & 948 & 1110 & 0.72 & 0.65 & 2.63 & 11.25 \\
\hline \multirow[t]{4}{*}{5.5} & 180 & 34.7 & 5.4 & 5.4 & 2280 & 2288 & 8.24 & 8.09 & 2041 & 2118 & 231 & 347 & 2.5 & 1.87 & 2.63 & 3.47 \\
\hline & 380 & 34.7 & 5.5 & 5.4 & 2280 & 2295 & 8.09 & 8.03 & 2111 & 2150 & 348 & 411 & 1.86 & 1.65 & 2.63 & 8.91 \\
\hline & 750 & 34.7 & 5.6 & 5.4 & 2280 & 2293 & 7.8 & 7.74 & 2215 & 2246 & 732 & 851 & 1.02 & 0.9 & 2.63 & 4.38 \\
\hline & 1150 & 34.7 & 5.6 & 5.4 & 2280 & 2299 & 7.66 & 7.63 & 2256 & 2283 & 1026 & 1104 & 0.76 & 0.71 & 2.63 & 12.28 \\
\hline \multirow[t]{4}{*}{8} & 180 & 34.7 & 8 & 7.6 & 2280 & 2290 & 8.26 & 8.12 & 2012 & 2092 & 223 & 322 & 2.8 & 2.15 & 2.63 & 7.3 \\
\hline & 380 & 34.7 & 7.9 & 7.6 & 2280 & 2293 & 8.11 & 8 & 2086 & 2146 & 333 & 445 & 2.11 & 1.68 & 2.63 & 15.22 \\
\hline & 750 & 34.7 & 7.9 & 7.5 & 2280 & 2302 & 7.81 & 7.73 & 2199 & 2247 & 711 & 876 & 1.15 & 0.96 & 2.63 & 16.18 \\
\hline & 1150 & 34.7 & 8.1 & 7.5 & 2280 & 2305 & 7.62 & 7.58 & 2256 & 2297 & 1138 & 1279 & 0.77 & 0.69 & 2.63 & 16.46 \\
\hline $\begin{array}{l}\text { Fjord } \\
(200 \mathrm{~m})\end{array}$ & & 35 & 3.9 & 4.3 & 2296 & 2287 & 7.98 & 8.03 & 2174 & 2145 & 448 & 398 & 1.45 & 1.61 & 3.27 & 3.13 \\
\hline
\end{tabular}

were arcsin transformed, and values for the ratio shell increment/diameter were Box-Cox transformed $(\lambda=2.467508)$. Data were tested for normality (Shapiro-Wilks test). In case of significant effects of temperature and/or $p \mathrm{CO}_{2}$, homogeneity of variances was tested with Levene's test. To determine significant differences between temperature and $p \mathrm{CO}_{2}$ treatments, respectively, a post-hoc Tukey's honest significant difference test (HSD or HSD for unequal $\mathrm{n}$, respectively) with $\alpha$-level 0.05 was used.

Raw scores for each shell degradation category as well as the compound score for shell degradation were analyzed using non-metric multidimensional scaling (NMDS). PERMANOVA was applied using all five shell degradation categories as response variables to test for significant effects of the factors temperature and $p \mathrm{CO}_{2}$ and possible interactions between factors. For NMDS and PERMANOVA Euclidean Distance was used to create a resemblance matrix. PERMANOVA was conducted according to a two-way crossed design (factors being temperature and $p \mathrm{CO}_{2}$ ) with type III partitioning of the sums of squares. Permutation of residuals under a reduced model was applied based on 9999 permutations to obtain the P-value, $\alpha$-level was 0.05 .

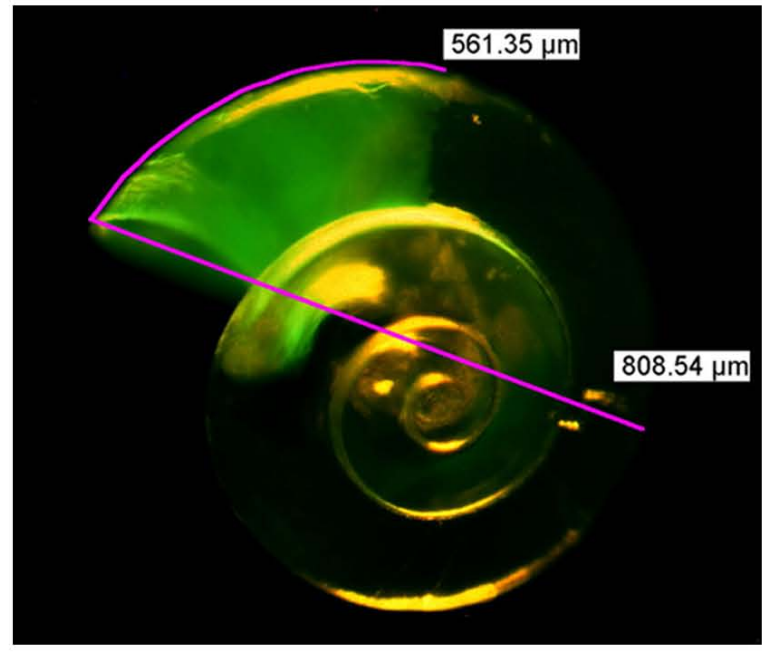

Fig. 5. Calcein stained shell of Limacina helicina showing shell increment during the experiment and measurement of increment length and diameter.

Statistics were carried out using Statistica version 8 (Statsoft) and PRIMER 6 (including PERMANOVA+, PRIMERe Ltd), respectively. 

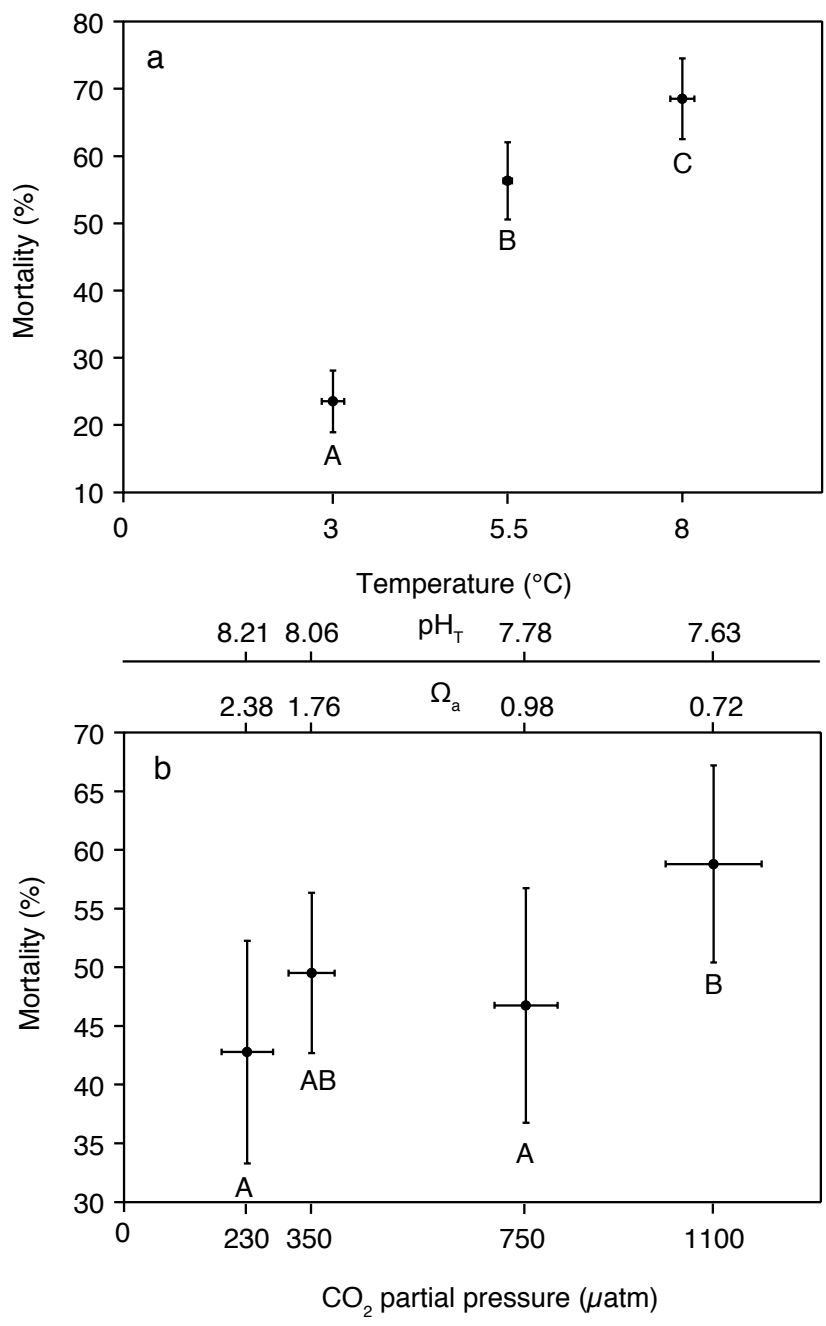

Fig. 6. Percent mortality after 29 days of incubation of Limacina helicina. Means for the effects of temperature (a) and $p \mathrm{CO}_{2}$ (b). Vertical bars denote 0.95 confidence intervals for mortality, horizontal bars denote 0.95 confidence intervals for temperature and $p \mathrm{CO}_{2}$, respectively. Results from the Tukey HSD post-hoc test are depicted by letters with levels not connected by same letter being significantly different.

\section{Results}

\subsection{Carbonate system}

Carbonate chemistry conditions of the fjord $\left(p \mathrm{CO}_{2}\right.$ of 448 $\pm 15 \mu \mathrm{atm}$ ) were roughly simulated in the $380 \mu \mathrm{atm}$ treatment as revealed by $A_{\mathrm{T}}, C_{\mathrm{T}}$ and temperature (Table 1). Compared to in situ conditions the $180 \mu$ atm treatment had an increased $\mathrm{pH}$ level and $\Omega_{a}$ whereas the $\mathrm{CO}_{2}$ enriched treatments had diminished $\mathrm{pH}$ levels and subsaturated $\Omega_{a}$ conditions. At the end of the experiment, $\mathrm{CO}_{2}$ partial pressures were higher compared to initial partial pressures. Accordingly $\mathrm{pH}$ and $\Omega_{a}$ levels were lower and $p \mathrm{CO}_{2}$ was higher. Interestingly, also $A_{\mathrm{T}}$ values were slightly higher.
Table 2. Univariate tests of significance indicating the effect of temperature and $p \mathrm{CO}_{2}$ on mortality. Significant results are represented in bold.

\begin{tabular}{lrrrrr}
\hline Effect & SS & df & MS & F & $p$ \\
\hline Intercept & 84.734 & 1 & 84.734 & 1362.562 & 0.000 \\
Temp & 7.469 & 2 & 3.735 & 60.055 & $\mathbf{0 . 0 0 0}$ \\
$p \mathrm{CO}_{2}$ & 1.088 & 3 & 0.363 & 5.831 & $\mathbf{0 . 0 0 0 9}$ \\
Temp $\times p \mathrm{CO}_{2}$ & 0.442 & 6 & 0.074 & 1.184 & 0.32 \\
Error & 8.209 & 132 & 0.062 & & \\
\hline
\end{tabular}

In the following, $p \mathrm{CO}_{2}$ values ( $\mu \mathrm{atm}$ ) shown in figures are the means of values measured at experimental start.

\subsection{Mortality}

Temperature and $p \mathrm{CO}_{2}$ both had a significant effect on mortality of Limacina helicina $(\mathrm{F}=60.055, p<0.0001$ and $\mathrm{F}=5.831, p=0.0009$, respectively) (Table 2). However, the temperature effect was stronger than the $p \mathrm{CO}_{2}$ effect (Fig. 6a and b). There were no interactions between both factors $(\mathrm{F}=1.184, p=0.32)$. Tukey HSD post-hoc test showed mortality to be significantly higher at $5.5^{\circ} \mathrm{C}$ and $8^{\circ} \mathrm{C}(p<0.0001$ and $p<0.0001$, respectively) than at in situ temperature $\left(3^{\circ} \mathrm{C}\right)$ (Fig. 6a). Moreover, mortality was significantly higher at $8^{\circ} \mathrm{C}$ than at $5.5^{\circ} \mathrm{C}(p=0.03) . p \mathrm{CO}_{2}$ caused a significantly higher mortality at $1100 \mu$ atm as compared to 230 and $750 \mu \mathrm{atm}$ ( $p<0.0001$ and $p=0.03$, respectively) (Fig. 6b), however, the mortality at $1100 \mu$ atm did not significantly differ from $350 \mu$ atm $(p=0.10)$.

\subsection{Shell degradation}

Ordination of the raw scores for each degradation category and the compound score by non-metric multidimensional scaling (NMDS) revealed differences in the effect size and direction of the factors temperature and $p \mathrm{CO}_{2}$. Furthermore, sizes and/or directions of factor effects were different within different levels of the other factor, thus implying interactions between both factors. Distances between data clouds showed that the effect size of the factor $p \mathrm{CO}_{2}$ was generally clearer and larger than the effect size of the factor temperature (Fig. 7). However, a temperature effect was specifically distinct for category $\mathrm{V}$ (perforation), where temperature has a clear and large effect within level four (1100 $\mu$ atm) of factor $p \mathrm{CO}_{2}$ (Fig. 7e). Moreover, temperature effects within all levels of factor $p \mathrm{CO}_{2}$ were larger in categories III, IV and $\mathrm{V}$ (scarred structures, corrosion, perforation) as compared to categories I, II (milky, brownish) and the compound value for all categories.

Statistical significance of factor effects was determined applying PERMANOVA. PERMANOVA revealed a significant 


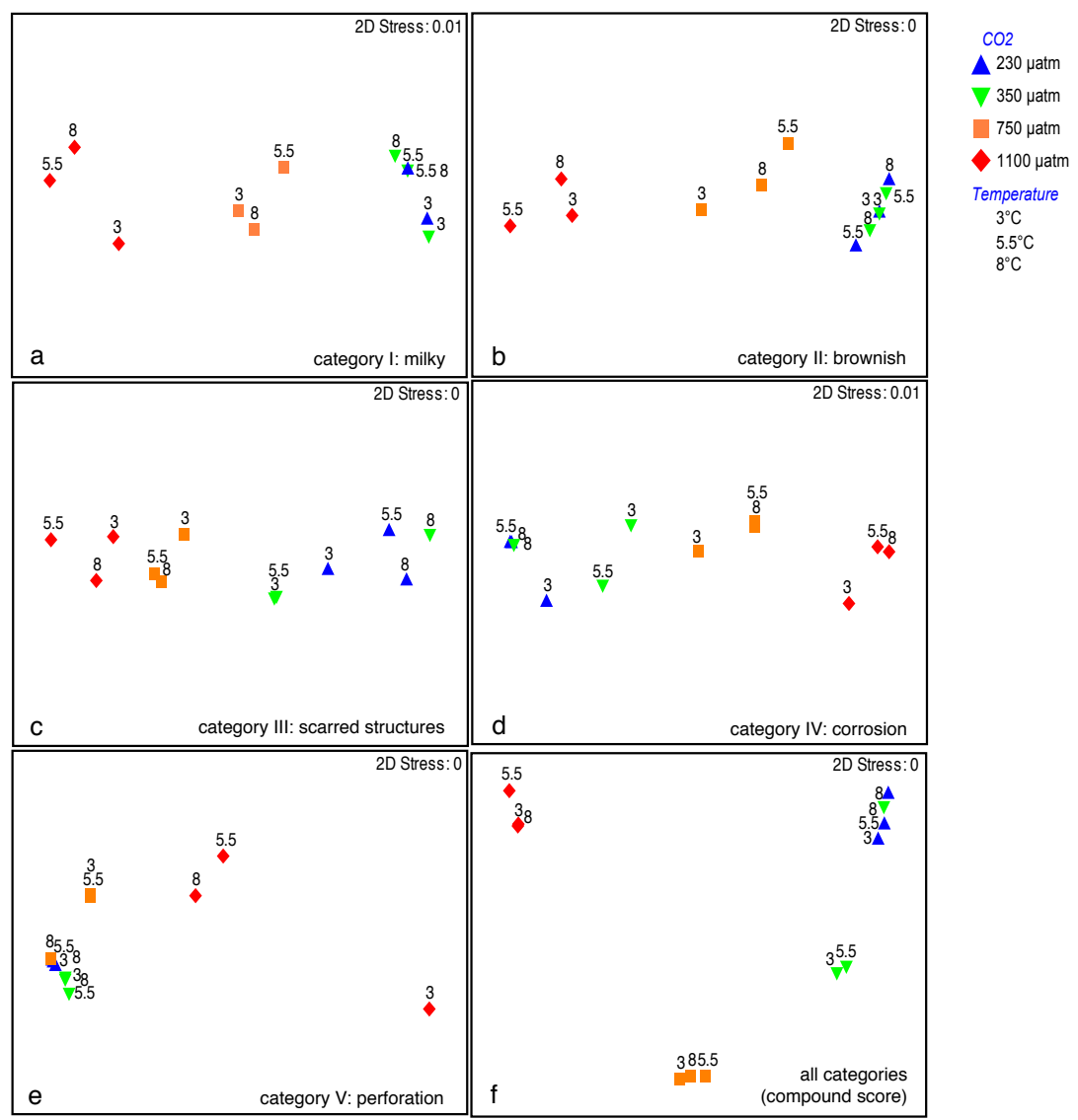

Fig. 7. MDS ordination of shell degradation categories with labels for the two-way crossed design: analyses of raw scores for each category (a to e) and of the compound value of all categories (f). 2-D stress is the goodness of the representation, i.e. a stress of $<0.05$ gives an excellent representation with no prospect of misinterpretation.

Table 3. PERMANOVA using all five shell degradation categories as response variables indicating the effect of temperature and $p \mathrm{CO}_{2}$ on shell degradation. Significant results are represented in bold.

\begin{tabular}{lrrrrrr}
\hline Source & df & SS & MS & Pseudo-F & P (perm) & Unique perms \\
\hline Temperature & 2 & 2.306 & 1.153 & 1.150 & 0.320 & 9938 \\
$p \mathrm{CO}_{2}$ & 3 & 146.03 & 48.678 & 48.565 & $\mathbf{0 . 0 0 0 1}$ & 9947 \\
Temp $\times p \mathrm{CO}_{2}$ & 6 & 9.560 & 1.593 & 1.590 & 0.095 & 9936 \\
Res & 60 & 60.139 & 1.002 & & & \\
Total & 71 & 220.36 & & & & \\
\hline
\end{tabular}

effect of $p \mathrm{CO}_{2}$ on shell degradation (Pseudo- $\mathrm{F}=48.565$, $\mathrm{P}$ (perm) $=0.0001$; Table 3$)$. The effect of temperature was not statistically significant (Pseudo-F $=1.1501, \mathrm{P}$ $($ perm $)=0.32)$, and no significant interaction between both factors was found (Pseudo-F $=1.59, \mathrm{P}($ perm $)=0.095)$. Pairwise tests for the factor $p \mathrm{CO}_{2}$ showed significant differences in shell degradation between all level combinations of $p \mathrm{CO}_{2}(\mathrm{P}($ perm $)=0.0001)$ except for the pair $230 / 350 \mu \mathrm{atm}$ $(P($ perm $)=0.361)($ Table 4, Fig. 3).

\subsection{Shell growth}

Univariate test of significance revealed a significant effect of $p \mathrm{CO}_{2}$ on shell diameter $(\mathrm{F}=4.955, \mathrm{df}=3, p=0.003)$ but not of temperature $(\mathrm{F}=1.767$, $\mathrm{df}=2, p=0.17$; Table not shown). Also, there was no significant interaction between the two factors $(\mathrm{F}=0.548, \mathrm{df}=6, p=0.76)$. Tukey HSD post-hoc test revealed shell diameter of the high $p \mathrm{CO}_{2}$ treatment $(1100 \mu \mathrm{atm})$ to be significantly lower than at $230 \mu \mathrm{atm}$ and $750 \mu \mathrm{atm}$, however, it was not significantly different from the $350 \mu$ atm treatment (Fig. 8). 


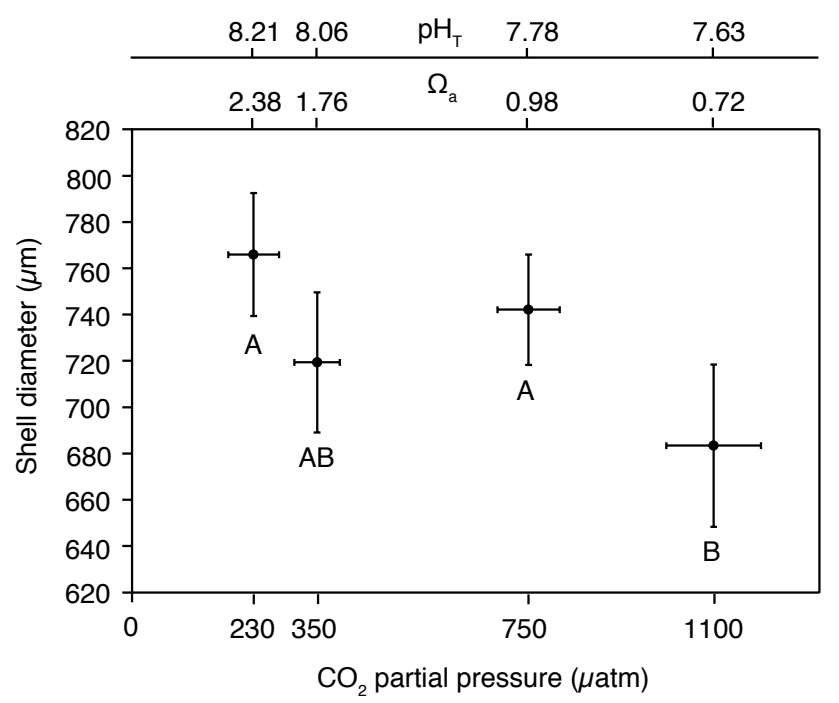

Fig. 8. Mean diameter of Limacina helicina after 29 days of incubation for the effect of $p \mathrm{CO}_{2}$. Vertical bars denote 0.95 confidence intervals for diameter, horizontal bars denote 0.95 confidence intervals for $p \mathrm{CO}_{2}$. Results from the Tukey HSD post-hoc test are depicted by letters with levels not connected by same letter being significantly different.

The ratio of shell increment versus diameter was significantly affected by $p \mathrm{CO}_{2}(\mathrm{~F}=4.344, p=0.008)$, but there was no significant effect of temperature $(\mathrm{F}=1.353$, $p=0.27)$ and no significant interaction between both factors $(\mathrm{F}=2.044, p=0.07$; Table 5). Tukey HSD post-hoc test revealed the shell increment/diameter ratio at the high $p \mathrm{CO}_{2}$ treatment $(1100 \mu \mathrm{atm})$ to be significantly lower than at 230 and $350 \mu \mathrm{atm}$, but not significantly different from the $750 \mu$ atm treatment (Fig. 9).

\section{Discussion}

The present experiments were carried out with unfed juvenile Limacina helicina; this species feeds on particles entangled in its mucus web, mainly on phytoplankton and small protozoa (Lalli and Gilmer, 1989). Phytoplankton biomass is low in Kongsfjorden already in late summer (Hop et al., 2002), and phytoplankton abundance was extremely low during the whole period of investigation (own observations from a $20 \mu \mathrm{m}$ net haul in the upper $20 \mathrm{~m}$ ). Moreover, L. helicina's downward migration to overwintering depth $(>100 \mathrm{~m})$ begins in the first half of September in Kongsfjorden (Lischka, unpublished data) and the larger part of the population already dwelled between 100 to $200 \mathrm{~m}$ in mid September (as determined by stratified vertical net hauls). Thus, feeding on phytoplankton can most likely be excluded. Rather lipid consumption during overwintering is likely (Gannefors et al., 2005) presumably at lower level metabolism (e.g. Lee et al., 2006). Although it is possible, that L. helicina still fed on
Table 4. PERMANOVA, Pair-wise tests for factor $p \mathrm{CO}_{2}$. Significant results are represented in bold.

\begin{tabular}{lrrr}
\hline Groups & $t$ & $\mathrm{P}($ perm) & $\begin{array}{r}\text { Unique } \\
\text { perms }\end{array}$ \\
\hline 230,350 & 1.027 & 0.3609 & 9946 \\
230,750 & 4.5986 & $\mathbf{0 . 0 0 0 1}$ & 9944 \\
230,1100 & 8.7309 & $\mathbf{0 . 0 0 0 1}$ & 9927 \\
350,750 & 6.1461 & $\mathbf{0 . 0 0 0 1}$ & 9941 \\
350,1100 & 11.556 & $\mathbf{0 . 0 0 0 1}$ & 9926 \\
750,1100 & 5.3049 & $\mathbf{0 . 0 0 0 1}$ & 9941 \\
\hline
\end{tabular}

Table 5. Univariate tests of significance indicating the effect of temperature and $p \mathrm{CO}_{2}$ on the ratio of shell increment to shell diameter. Significant results are represented in bold.

\begin{tabular}{lrrrrr}
\hline & SS & df & MS & F & $p$ \\
\hline Intercept & 34.772 & 1 & 34.772 & 4249.554 & 0.000 \\
Temp & 0.022 & 2 & 0.011 & 1.353 & 0.27 \\
$p \mathrm{CO}_{2}$ & 0.107 & 3 & 0.036 & 4.344 & $\mathbf{0 . 0 0 8}$ \\
Temp $\times p \mathrm{CO}_{2}$ & 0.100 & 6 & 0.017 & 2.044 & 0.07 \\
Error & 0.507 & 62 & 0.008 & & \\
\hline
\end{tabular}

organic particles during this time of the year, which could affect the effect size of temperature and $p \mathrm{CO}_{2}$ on the response of $L$. helicina, a change in effect direction is unlikely since individuals in all treatments were kept under the same conditions with respect to food.

\subsection{Carbonate system}

$A_{\mathrm{T}}$ at the end of the experiment showed a slightly increased trend with increasing temperature and $p \mathrm{CO}_{2}$ that correlates with silicate concentrations. Most likely the $A_{\mathrm{T}}$ increase resulted from silicate and other components dissolved from the experimental jars.

Increased $C_{\mathrm{T}}$ concentrations and therefore decreased $\mathrm{pH}$ and $\Omega$ values as well as increased $\mathrm{CO}_{2}$ partial pressures at the end are most likely explained by respiration of pteropods (and bacteria) in the closed experimental set up.

\subsection{Effects of elevated temperature}

Concerning mortality, temperature was the dominant factor as revealed by the higher $\mathrm{F}$ and lower $p$ value compared to those associated with $p \mathrm{CO}_{2}$ (Table 2). Limacina helicina at the beginning of the overwintering phase are very sensitive to changes of 3 to $5^{\circ} \mathrm{C}$. L. helicina is a north Atlantic/polar species that is adapted to a relatively narrow and low temperature range between $-0.4{ }^{\circ} \mathrm{C}$ and $+4{ }^{\circ} \mathrm{C}$ and infrequently up to $7^{\circ} \mathrm{C}$ (van der Spoel, 1967; Bé and Gilmer, 1977). As 


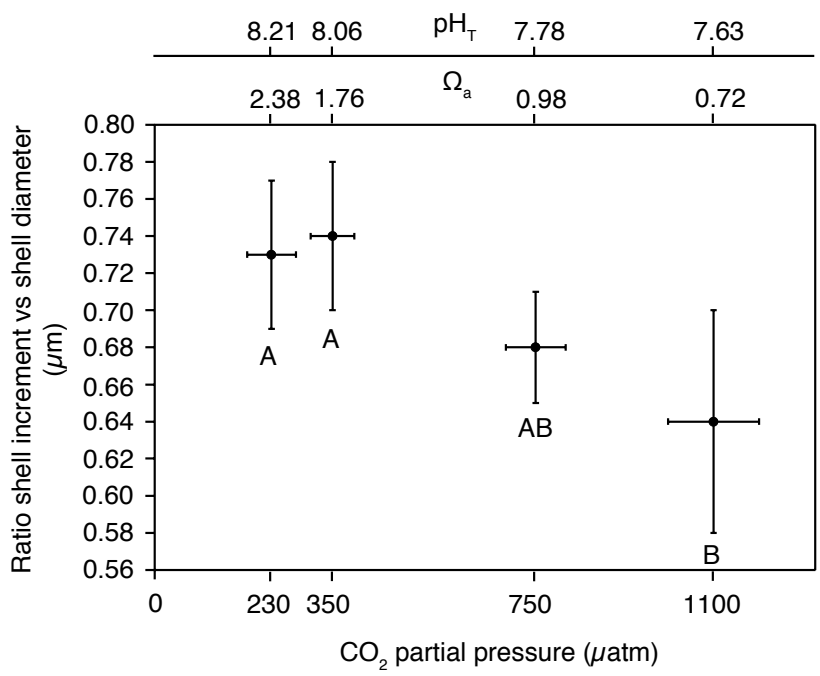

Fig. 9. Mean ratio of shell increment to diameter of Limacina helicina after 29 days of incubation for the effect of $p \mathrm{CO}_{2}$. Vertical bars denote 0.95 confidence intervals for mean ratio while horizontal bars denote 0.95 confidence intervals for $p \mathrm{CO}_{2}$. Results from the Tukey HSD post-hoc test are depicted by letters with levels not connected by same letter being significantly different.

mentioned earlier, peak occurrence of L. helicina during the present investigation was between 100 and $200 \mathrm{~m}$ depth. In September/October 2009, a relatively warm water lens of about 5 to $5.5^{\circ} \mathrm{C}$ occurred in Kongsfjorden between 40 and $110 \mathrm{~m}$ depth. Below $110 \mathrm{~m}$, temperature decreased quickly to values below $4{ }^{\circ} \mathrm{C}$ down to a minimum of about $2{ }^{\circ} \mathrm{C}$ at $300 \mathrm{~m}$. Furthermore, at the time of this investigation, $L$. helicina was at the onset of the overwintering period presumably not feeding anymore, likely living on lipid reserves. Temperature adaptation is a complex and costly metabolic response and costs of existence (the sum of all processes that are necessary to maintain viability, excluding reproduction, growth, and activity) vary significantly with temperature (Clarke, 2003). Hence, temperature stress during this period of $L$. helicina's life cycle can be a severe threat for its ability not only to survive the food-scarce winter period, but to survive with still enough energy reserves available to proceed development to adults and fuel reproduction in spring/summer.

\subsection{Effects of elevated $p \mathrm{CO}_{2}$}

\subsubsection{Shell increment and shell diameter}

Similar to Reusch (1998), calcein was used here as a qualitative measure of shell growth. In juvenile L. helicina, staining was not only depicted as a distinct green line at the growing margin, but usually two main regions of coloration indicating calcification activity were observed. One region usually started with a distinct line on the outer whorl extending to
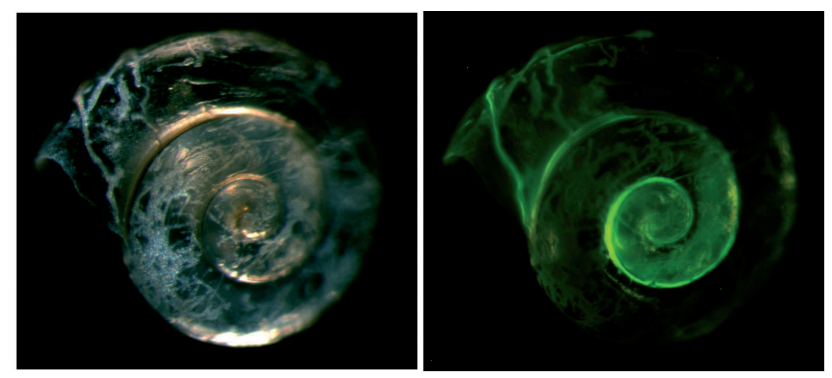

Fig. 10. Example for "repair" calcification: shell degradation of Limacina helicina (left, oblique transmitted light) and the respective regions of "repair" calcification indicated by enhanced fluorescence due to calcein incorporation (right).

the aperture (the actual shell increment - in terms of lengthening), the other was found around the protoconch. This is in contrast to Comeau et al. (2009) who reported a distinct green line marking the shell edge (apertural margin) at the time of staining. The findings presented here are proposed as indication of "repair" calcification, since regions of coloration usually showed up where shell integrity was affected (Fig. 10). Indeed, thecosomes are able to repair shell parts (van der Spoel, 1967).

The question arising from this is why the region defined as shell increment was completely green instead of a single line marking the shell edge at time of staining and whether or not this region is indeed incremental or rather a region of enhanced shell thickening (in terms of increase of shell thickness) at the inner surface (presumably the inner prismatic layer, Sato-Okoshi et al., 2010)? Concomitant shell diameter measurements on juveniles freshly caught in the field during the whole period of the experiment (data not shown) as well as the increasing shell diameters of the incubated individuals indicate growth of juvenile L. helicina during September/October 2009. To further address this question, shell cross sections were made and revealed a fluorescence band at the inner shell surface, implying inward shell thickening (Fig. 11a and b). However, close to the aperture, the whole shell cross section (sensu Sato-Okoshi et al., 2010 the outer prismatic, middle crossed-lamellar, and inner prismatic layer) was fluorescent, thus implying shell increment (Fig. 11c). This region is suggested to exhibit shell increment, where the proximal ("older") part of new increment is still thickened inwardly (inner prismatic layer), and close to the apertural margin true shell increment proceeds. A similar process was described for the pteropod Cuvierina columnella (Cavoliniidae), which after attaining maximum shell length continues to thicken the entire shell inwardly (Lalli and Gilmer, 1989). Moreover, if our hypothesis is true for $L$. helicina, the fact that the entire region of increment was green points to storage of calcein during the entire incubation time. 

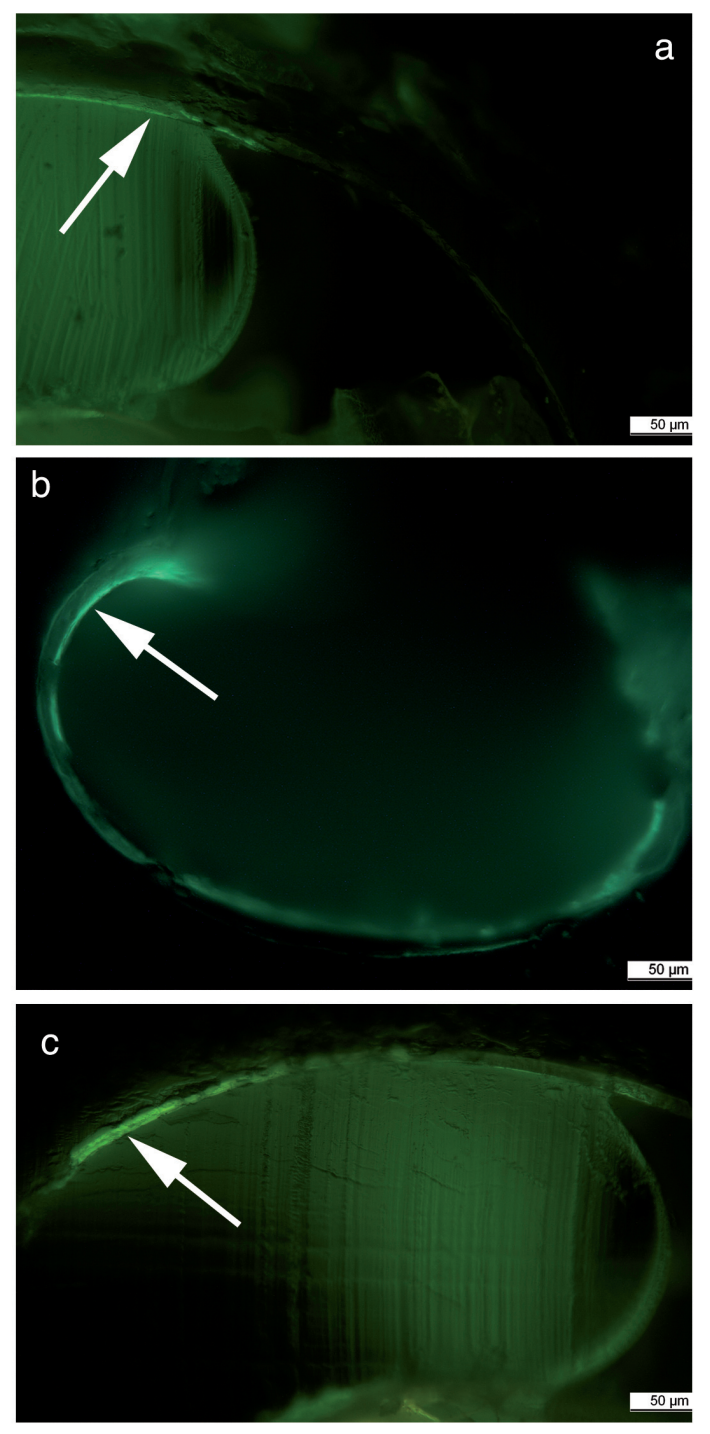

Fig. 11. Cross sections of Limacina helicina shells in the region of shell increment. (a) Dorso-lateral section (higher magnification of the right part of (c) showing a fluorescence band at the inner shell surface, arrow pointing at the thin inner fluorescence line). (b) Cross section of the aperture region distal from the area of increment, the arrow pointing at the line of constructive processes at the inner prismatic shell layer. (c) Dorso-lateral section showing calcein incorporation in all shell layers (prismatic, middle crossedlamellar, inner prismatic) close to the aperture (arrow).

Shell growth of Limacina helicina kept at $1100 \mu$ atm was significantly reduced as compared to individuals kept at 350 and $230 \mu \mathrm{atm}$ (Fig. 9). However, L. helicina was able to grow at $\Omega_{a}<1$. Consequently, the present results principally agree with the conclusion by Comeau et al. (2009) deduced from adult $L$. helicina that seemed to be relatively well adapted to aragonite undersaturation. However, in addition to shell growth, shell degradation state of juvenile L. helicina revealed pronounced dissolution processes at the same time and as mentioned earlier, "repair" calcification is suggested. Therefore, three crucial questions arise: (1) How well can juvenile L. helicina adapt to aragonite undersaturation?, (2) What are the costs for different life stages of $L$. helicina to facilitate calcification and repair dissolution damage under aragonite undersaturation?, and (3) Will it be possible for L. helicina to maintain the integrity of its shell and, at the same time, sustain development, reproduction and accumulation of energy reserves to overwinter? The intensity of shell degradation under the two highest $p \mathrm{CO}_{2}$ levels leads to the conclusion that juvenile pre-winter L. helicina may be seriously threatened under aragonite undersaturation.

The present study shows that $p \mathrm{CO}_{2}$ is the driving factor influencing shell growth and calcification of juvenile $L$. helicina, whereas for temperature no significant influence was detected. This is in agreement with recent findings for adult $L$. helicina that exhibited declined precipitation rates of $\mathrm{CaCO}_{3}$ as a function of $p \mathrm{CO}_{2}$ (Comeau et al., 2010b). However, inconclusive results with respect to a temperature effect in the present study might be due to i.e. experimental constraints (i.e. experiment/test could not detect an effect) and does not necessarily mean that temperature had no effect.

\subsubsection{Shell degradation}

Both elevated $p \mathrm{CO}_{2}$ levels caused a significant effect on shell degradation, especially at $1100 \mu \mathrm{atm}$ (Fig. 3). Hence, shell degradation state gives clear evidence that the shell of juvenile L. helicina is negatively affected by aragonite saturation levels below 1. To the authors knowledge dissolution in live pteropods has so far only been reported by Orr et al. (2005) and Comeau et al. (2010a) from a Subarctic Pacific and a Mediterranean species, respectively (Clio pyramidata and Cavolinia inflexa). Similar to the present results, shell surface alterations due to $\mathrm{CaCO}_{3}$ undersaturation are reported by e.g. Green et al. (2009) on live juvenile benthic bivalves, and from Limacina spp. shells collected in sediment traps by Gerhardt et al. (2000) and Manno et al. (2007).

PERMANOVA neither revealed a significant effect for temperature nor significant interactions between the two factors but P-value for the interaction term was quite small and thus rather inconclusive (Table 3). Although not statistically significant, NMDS ordination (Fig. 7), however, suggests that temperature may have an influence on shell degradation as well as the occurrence of interactive effects between temperature and $p \mathrm{CO}_{2}$ are suggested. The ordination of the $3{ }^{\circ} \mathrm{C}$ and $1100 \mu$ atm $\mathrm{CO}_{2}$ treatment in Fig. $7 \mathrm{e}$ shows a clear and large temperature effect. Highest incidence of perforated shells was at ambient temperature and high $p \mathrm{CO}_{2}$, whereas at higher temperatures shells were considerably corroded but less perforated. Hence, at higher temperature and perhaps due to a higher metabolism, L. helicina might be better able to counteract dissolution processes by 'repair' calcification and therefore avoid perforation at least for a limited time. Similarly, McDonald et al. (2009) 
describe compensatory calcification in the intertidal barnacle Amphibalanus amphitrite that was exposed to acidified conditions and showed compensatory calcification of their basal shell plates but central shell wall plates were significantly weakened.

\section{Conclusion}

The findings shown here give insight to the response (with respect to mortality, shell degradation and shell increment) of juvenile Limacina helicina just before overwintering as a function of temperature and $p \mathrm{CO}_{2}$. Increased temperature and $p \mathrm{CO}_{2}$ act differently on L. helicina, both significantly increasing species mortality but only the latter significantly affecting shell integrity and shell growth. $p \mathrm{CO}_{2}$ change projected for the near future may severely affect pre-winter juveniles, and rising temperatures could contribute to a decline in abundance of the overwintering population, which represents the basis for next year's reproduction. Hence, population dynamics are likely to be changed and consequences for the Arctic epipelagic ecosystem may arise.

Various questions arise from this study with respect to $L$. helicina's fate in a high $\mathrm{CO}_{2}$ ocean. This study suggests higher metabolic activity and thus higher metabolic costs to compensate for dissolution and as possible reason for higher mortality of L. helicina at higher temperature (Wood et al., 2008; Comeau et al., 2010b; Thomsen and Melzner, 2010). This raises the question as to energetic costs/trade offs and to what extent compensatory metabolic costs can be tolerated without seriously threatening winter survival and ultimately reproductive success? To address these questions, detailed physiological studies of the effects of rising $\mathrm{CO}_{2}$ and temperature on different life stages of Limacina helicina are needed (e.g. respiration, lipid utilization).

\section{Supplementary material related to this article is available online at: http://www.biogeosciences.net/8/919/2011/ bg-8-919-2011-supplement.pdf.}

Acknowledgements. We thank the staffs of the AWIPEV Station of the Alfred-Wegener-Institute for Polar and Marine Research and Kings Bay AS in Ny-Ålesund for excellent logistical support during our field campaign. The Institute for Polar Ecology in Kiel is acknowledged for making logistics and optical facilities available to us. The scanning electron microscopy work was performed in the Institute of Geosciences in Kiel, particularly we are indebted to Ute Schuldt for her supervision in the SEM Lab. Thanks are also due to Armin Form for helpful discussions. Dieter Piepenburg (Institute for Polar Ecology) provided access to PERMANOVA + for PRIMER. We also thank Jon Havenhand and an anonymous referee for their valuable suggestions and critics on the manuscript. This work is a contribution to the German BMBF (Federal Ministry of Education and Research) funded project "Biological Impacts of Ocean Acidification" (BIOACID, Grant number 03F0608A) as well as to the "European Project on Ocean Acidification" (EPOCA) which received funding from the European Community's Seventh Framework Programme (FP7/2007-2013) under grant agreement $\mathrm{n}^{\circ}$ 211384. This work also received funding from the European Centre for Arctic Environmental Research (ARCFAC, Grant number 026129-2008-54).

Edited by: J.-P. Gattuso

\section{References}

Acker, J. G. and Byrne, R. H.: The influence of surface state and saturation state on the dissolution kinetics of biogenic aragonite in seawater, Am. J. Sci., 289, 1098-1116, 1989.

Almogi-Labin, A., Luz, B., and Duplessy, J.-C.: Quaternary paleooceanography, pteropod preservation and stable-isotope record of the Red Sea, Paleogr. Paleoclimatol. Paleoecol., 57, 195-211, 1986.

Bathmann, U. V., Noji, T. T., and von Bodungen, B.: Sedimentation of pteropods in the Norwegian Sea in autumn, Deep-Sea Res., 38, 1341-1360, 1991.

Bé, A. W. H. and Gilmer, R. W.: A zoogeographic and taxonomic review of euthecosomatous Pteropoda, in: Oceanic micropalaeontology, edited by: Ali, M. A., Academic Press, London, 773-808, 1977.

Berner, R. A. and Honjo, S.: Pelagic sedimentation of aragonite: its geochemical significance, Science, 211, 940-942, 1981.

Bradshaw, A. L., Brewer, P. G., Shafer, D. K., and Williams, R. T.: Measurements of total carbon dioxide and alkalinity by potentiometric titration in the GEOSECS program, Earth Planet Sci. Lett., 55, 99-115, 1981.

Clark, D., Lamare, M., and Barker, M.: Response of sea urchin pluteus larvae (Echinodermata: Echinoidea) to reduced seawater $\mathrm{pH}$ : a comparison among a tropical, temperate, and a polar species, Mar. Biol., 156, 1125-1137, 2009.

Clarke, A.: Costs and consequences of evolutionary temperature adaptation, Trends Ecol. Evol., 18, 573-581, 2003.

Comeau, S., Gorsky, G., Jeffree, R., Teyssié, J.-L., and Gattuso, J.-P.: Impact of ocean acidification on a key Arctic pelagic mollusc (Limacina helicina), Biogeosciences, 6, 1877-1882, doi:10.5194/bg-6-1877-2009, 2009.

Comeau, S., Gorsky, G., Alliouane, S., and Gattuso, J. P.: Larvae of the pteropod Cavolinia inflexa exposed to aragonite undersaturation are viable but shell-less, Mar. Biol. 157, 2341-2345, 2010a.

Comeau, S., Jeffree. R., Teyssié, J. L., and Gattuso, J. P.: Response of the Arctic Pteropod Limacina helicina to Projected Future Environmental Conditions PLoS ONe, 5(6), e11362, $2010 \mathrm{~b}$.

Dickson, A. G. and Millero, F. J.: A comparison of the equilibrium constants for the dissociation of carbonic acid in seawater media, Deep-Sea Res Part A, 34, 1733-1743, 1987.

Dickson, A. G., Afghan, J. D., and Anderson, G. C.: Reference materials for oceanic $\mathrm{CO}_{2}$ analysis: a method for the certification of total alkalinity, Mar. Chem., 80, 185-197, 2003.

Dickson, A. G., Sabine, C. L., and Christian, J. R. (Eds.): Guide to the best practices for ocean $\mathrm{CO}_{2}$ measurements, PICES Special Publication, 3, 191 pp., 2007.

Fabry, V. J., Seibel, B. A., Feely, R. A., and Orr, J. C.: Impacts of ocean acidification on marine fauna and ecosystem processes, ICES J. Mar. Sci., 65, 414-432, 2008. 
Falk-Petersen, S., Sargent, J. R., Kwasniewski, S., Gulliksen, B., and Millar, R. M.: Lipids and fatty acids in Clione limacina and Limacina helicina in Svalbard waters and the Arctic Ocean: trophic implications, Polar Biol., 24, 163-170, 2001.

Gannefors, C., Böer, M., Kattner, G., Graeve, G., Eiane, K., Gulliksen, B., Hop, H., and Falk-Petersen, S.: The Arctic sea butterfly Limacina helicina: lipids and life strategy, Mar. Biol., 147, 169177, 2005.

Gattuso, J.-P., Allemand, D., and Frankignoulle, M.: Photosynthesis and calcification at cellular, organismal and community levels in coral reefs: a review on interactions and control by carbonate chemistry, Am. Zool., 39, 160-183, 1999.

Gazeau, F., Quiblier, C., Jansen, J. M., Gattuso, J.-P., Middelburg, J. J., and Heip, C. H. R.: Impact of elevated $\mathrm{CO}_{2}$ on shellfish calcification, Geophys. Res. Lett., 34, L07603, doi:10.1029/2006GL028554, 2007.

Gerhardt, S., Groth, H., Ruehlemann, C., and Henrich, R.: Aragonite preservation in late Quaternary sediment cores on the Brazilian Continental Slope: implications for intermediate water circulation, Int. J. Earth Sci., 88, 607-618, 2000.

Gilmer, R. W. and Harbison, G. R.: Diet of Limacina helicina (Gastropoda: Thecosomata) in Arctic waters in midsummer, Mar. Ecol. Prog. Ser., 77, 125-134, 1991.

Green, M. A., Waldbusser, G. G., Reilly, S. L., Emerson, K., and O'Donnell, S.: Death by dissolution: Sediment saturation state as a mortality factor for juvenile bivalves, Limnol. Oceanogr., 54, 1048-1059, 2009.

Guinotte, J. M. and Fabry, V. J.: Ocean Acidification and Its Potential Effects on Marine Ecosystems, Ann. NY Acad. Sci., 1134, 320-342, 2008.

Gutowska, M. A., Melzner, F., Pörtner, H. O., and Meier, S.: Cuttlebone calcification increases during exposure to elevated seawater $p \mathrm{CO}_{2}$ in the cephalopod Sepia officinalis, Mar. Biol., 157, 1653$1663,2010$.

Haddad, G. A. and Droxler, A. W.: MetasTable $\mathrm{CaCO}_{3}$ dissolution at intermediate water depths of the Caribbean and western North Atlantic: Implications for intermediate water circulation during the past 200000 years, Paleoceanography, 11, 701-716, 1996.

Hagen, W. and Auel, H.: Seasonal adaptations and the role of lipids in oceanic zooplankton, Zoology, 104, 313-326, 2001.

Hirche, H.-J.: Diapause in the marine copepod, Calanus finmarchicus - a review, Ophelia, 44, 129-143, 1996.

Hop, H., Pearson, T., Hegseth, E. N., Kovacs, K. M., Wiencke, C., Kwasniewski, S., Eiane, K., Mehlum, F., Gulliksen, B., Wlodarska-Kowalczuk, M., Lydersen, C., Weslawski, J. M., Cochrane, S., Gabrielsen, G. W., Leakey, R. J. G., Lønne, O. J., Zajaczkowski, M., Falk-Petersen, S., Kendall, M., Wängberg, S.-Å., Bischof, K., Voronkov, A. Y., Kovaltchouk, N. A., Wiktor, J., Poltermann, M., di Prisco, G., Papucci, C., and Gerland, S.: The marine ecosystem of Kongsfjorden, Svalbard, Polar Res., 21, 167-208, 2002.

Hunt, B. P. V., Pakhomov, E. A., Hosie, G. W., Siegel, V., Ward, P. and Bernard, K.: Pteropods in Southern Ocean ecosystems, Prog. Oceanogr., 78, 193-221, 2008.

Karnovsky, N. J., Hobson, K. A., Iverson, S., and Hunt, G. L.: Seasonal changes in diets of seabirds in the North Water Polynya: a multiple-indicator approach, Mar. Ecol. Prog. Ser., 357, 291299, 2008.

Koroleff, F. and Grasshoff, K.: Determination of nutrients, in: Methods of seawater analysis, edited by: Grasshoff, K., Ehrhardt, M., Kremling, K., Verlag Chemie, Weinheim, 419 pp., 1983.

Kurihara, $\mathrm{H}$.: Effects of $\mathrm{CO}_{2}$-driven ocean acidification on the early developmental stages of invertebrates, Mar. Ecol. Prog. Ser., 373, 275-284, 2008.

Kurihara, H., Kato, S., and Ishimatsu, A.: Effects of increased seawater $\mathrm{pCO}_{2}$ on early development of the oyster Crassostrea gigas, Aquat. Biol., 1, 91-98, 2007.

Lalli, C. M. and Gilmer, R. W.: Pelagic snails: the biology of holoplanktonic gastropod molluscs, Stanford University Press, 1989.

Lee, R. F., and Hagen, W., and Kattner, G.: Lipid storage in marine zooplankton, Mar. Ecol. Prog. Ser., 307, 273-306, 2006.

Manno, C., Sandrini, S., Tositti, L. and Accornero, A.: First stages of degradation of Limacina helicina shells observed above the aragonite chemical lysocline in Terra Nova Bay (Antarctica), J. Mar. Syst., 68, 91-102, 2007.

McDonald, M. R., McClintock, J. B., Amsler, C. D., Rittschof, D., Angus, R. A., Orihuela, B., and Lutostanski, K.: Effects of ocean acidification over the life history of the barnacle Amphibalanus amphitrite, Mar. Ecol. Prog. Ser., 385, 179-187, 2009.

Mehrbach, C., Culberson, C. H., Hawley, J. E., and Pytkowicz, R. M.: Measurement of the apparent dissociation constants of carbonic acid in seawater at atmospheric pressure, Limnol. Oceanogr., 18, 897-907, 1973.

Orr, J. C., Fabry, V.J., Aumont, O., Bopp, L., Doney, S.C., Feely, R.A., Gnanadesikan, A., Gruber, N., Ishida, A., Joos, F., Key, R. M., Lindsay, K., Maier-Reimer, E., Matear, R., Monfray, P., Mouchet, A., Najjar, R. G., Plattner, G.-K., Rodgers, K. B., Sabine, C. L., Sarmiento, J. L., Schlitzer, R., Slater, R. D., Totterdell, I. J., Weirig, M.-F., Yamanaka, Y., and Yool, A.: Anthropogenic ocean acidification over the twenty-first century and its impact on calcifying organisms, Nature, 437, 681-686, 2005.

Pierrot, D. E. L. and Wallace, D. W. R.: MS Excel program developed for $\mathrm{CO}_{2}$ System Calculations. ORNL/CDIAC-105, Oak Ridge, Tennessee, Carbon Dioxide Information Analysis Center, Oak Ridge National Laboratory, US Department of Energy, 2006.

Reusch, T. B. H.: Differing effects of eelgrass Zostera marina on recruitment and growth of associated blue mussels Mytilus edulis, Mar. Ecol. Prog. Ser., 167, 149-153, 1998.

Riebesell, U., Zondervan, I., Rost, B., Tortell, P. D., Zeebe, R. E., and Morel, F. M. M.: Reduced calcification of marine plankton in response to increased atmospheric $\mathrm{CO}_{2}$, Nature, 407, 364-367, 2000.

Sato-Okoshi, W., Okoshi, K., Sasaki, H., and Fumihiro, A.: Shell structure of two polar pelagic molluscs, Arctic Limacina helicina and Antarctic Limacina helicina antarctica forma antarctica, Polar Biol., 33, 1577-1583, 2010.

Seibel, B. A., Dymowska, A., and Rosenthal, J.: Metabolic temperature compensation and coevolution of locomotory performance in pteropod molluscs, Integr. Comp. Biol., 47, 880-891, 2007.

Steinacher, M., Joos, F., Frölicher, T. L., Plattner, G.-K., and Doney, S. C.: Imminent ocean acidification in the Arctic projected with the NCAR global coupled carbon cycle-climate model, Biogeosciences, 6, 515-533, doi:10.5194/bg-6-515-2009, 2009.

Stoll, M. H. C., Bakker, K., Nobbe, G. H., and Haese, R. R.: Continuous-Flow Analysis of Dissolved Inorganic Carbon Content in Seawater, Anal. Chem., 73, 4111-4116, 2001. 
Thomsen, J. and Melzner, F.: Moderate seawater acidification does not elicit long-term metabolic depression in the blue mussel Mytilus edulis, Mar. Biol., 157, 2667-2676, 2010.

van der Spoel, S. V. D.: Euthecosomata a group with remarkable developmental stages (Gastropoda, Pteropoda), Zoological Museum, Amsterdam, 375 pp., 1967.

Wilson, J. G.: Environment and birth defects, Academic, New York, 1973.
Wood, H. L., Spicer, J. I., and Widdicombe, S.: Ocean acidification may increase calcification rates, but at a cost, Proc. Royal Soc. London, Series B: Biol. Sci., 275, 1767-1773, 2008.

Yamamoto-Kawai, M., McLaughlin, F. A., Carmack, E. C., Nishino, S., and Shimada, K.: Aragonite understauration in the Arctic Ocean: effects of ocean acidification and sea ice melt, Science, 1098-1100, 2009. 